Article

\title{
Synthesis and Characterization of Triphenylphosphine Adducts of Ferrocene-Based Palladacycles and Their Performance in the Suzuki and Sonogashira Reactions with Bromo- and Chloroarenes
}

\author{
Su-Zhen Bai ${ }^{1}$, Chen Xu ${ }^{2, *}$, Hong-Mei $\mathrm{Li}^{2}$, Zhi-Qiang Wang ${ }^{2}$ and Wei-Jun Fu ${ }^{2}$ \\ 1 College of Chemistry and Chemical Engineering, Pingdingshan University, Pingdingshan, \\ Henan 467002, China \\ 2 College of Chemistry and Chemical Engineering, Luoyang Normal University, Luoyang, \\ Henan 471022, China \\ * Author to whom correspondence should be addressed; E-Mail: xubohan@163.com; \\ Tel.: +86-379-6551-5113.
}

Received: 12 April 2012; in revised form: 3 May 2012 / Accepted: 4 May 2012 /

Published: 9 May 2012

\begin{abstract}
A new triphenylphosphine adduct of cyclopalladated ferrocenylpyridazine containing a chloride anion, 2a, has been synthesized from the reaction of the chloride-bridged palladacyclic dimer 1a with triphenylphosphine. The corresponding adducts $\mathbf{3 a}, \mathbf{b}$ containing iodide anion have been readily prepared through anion exchange reactions of $\mathbf{2 a}, \mathbf{b}$ with $\mathrm{NaI}$ in acetone. These complexes were characterized by elemental analysis, IR and ${ }^{1} \mathrm{H}-\mathrm{NMR}$. Additionally, their crystal structures have been determined by $\mathrm{X}$-ray diffraction and intermolecular $\mathrm{C}-\mathrm{H} \cdots \mathrm{X}(\mathrm{Cl}, \mathrm{Br}, \mathrm{I})$ bonds were found in the crystals. The use of these palladacycles as catalysts for the Suzuki and Sonogashira reactions was examined. The complexes $\mathbf{2 a}, \mathbf{b}$ exhibited higher catalytic activity than the corresponding $\mathbf{3 a}, \mathbf{b}$ in the Suzuki reaction. However, the order of activity of adducts with varying halogen anions is $\mathbf{3 a} \sim \mathbf{3 b}>\mathbf{2} \mathbf{a} \sim \mathbf{2} \mathbf{b}$ in the Sonogashira reaction.
\end{abstract}

Keywords: adduct; palladacycle; crystal structure; Suzuki reaction; Sonogashira reaction 


\section{Introduction}

Palladium-catalyzed coupling reactions such as the Suzuki and Sonogashira reactions have become an extremely powerful method for the formation of carbon-carbon bonds in organic synthesis [1-3]. A number of Pd catalyst precursors, usually simple palladium salts or complexes associated with appropriate ligands, can catalyse these reactions under various reaction conditions. Among them, palladacycles have been extensively applied in coupling reactions as effective catalyst precursors, due to their ready preparation and modification, high activity and relative stability [4-6]. In the cyclopalladation reactions, owing to the poor solubility of the dimers, they are usually subjected to a bridge-splitting reaction with monophosphines to produce the corresponding adducts.

In recent years, we have reported a variety of cyclometalated complexes containing $\mathrm{N}$-donor ferrocenyl ligands and found that palladacycle adducts were far more active than the corresponding dimers in coupling reactions [7-9]. In view of these findings and our continuing interest in the synthesis of palladacycles and the applications of these systems, we have prepared a new chloride anion-containing palladacycle adduct $\mathbf{2 a}$ and two corresponding adducts $\mathbf{3 a}, \mathbf{b}$ containing iodide anion (Scheme 1). Their application to the Suzuki and Sonogashira reactions were investigated since we were interested to see the effect of halogen anions on the catalytic activity. The results are described in this paper.

Scheme 1. Synthesis of triphenylphosphine adducts of palladacycles 2-3.

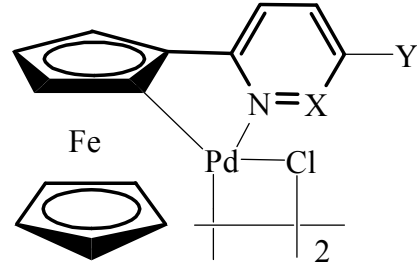

$1(\mathbf{a}, \mathbf{b})$

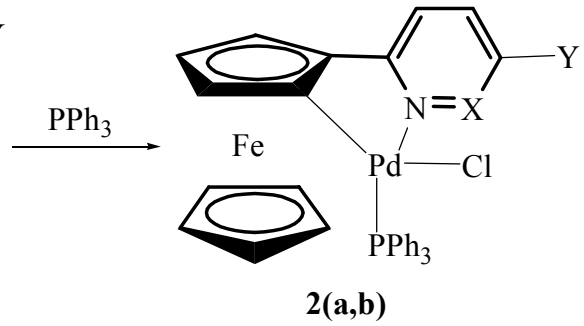

$2(\mathbf{a}, \mathbf{b})$

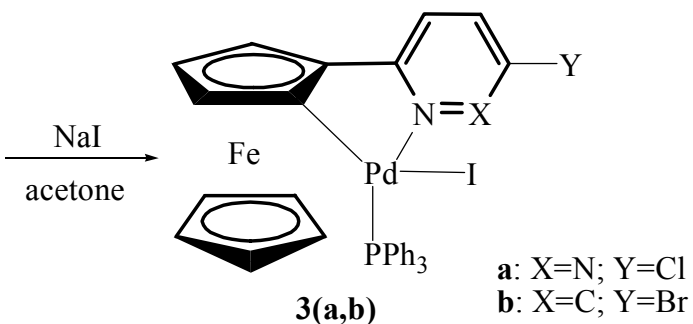

3(a,b) b: $\mathrm{X}=\mathrm{C} ; \mathrm{Y}=\mathrm{Br}$

\section{Results and Discussion}

\subsection{Synthesis and Characterization of Complexes $\mathbf{2}-\mathbf{3}$}

The chloride-bridged palladacyclic dimers 1a,b were prepared according to the published procedures $[10,11]$. Then each of them was treated with 1.1 equivalent of triphenylphosphine per palladium in $\mathrm{CH}_{2} \mathrm{Cl}_{2}$ at room temperature for $30 \mathrm{~min}$ to afford the corresponding adducts $\mathbf{2 a}$, $\mathbf{b}$ as red solids. The iodide anion-containing palladacycle adducts $\mathbf{3 a}, \mathbf{b}$ have been readily prepared through anion exchange reactions of $\mathbf{2 a}, \mathbf{b}$ with $\mathrm{NaI}$ in acetone (Scheme 1). These complexes are air- and moisture-stable, both in the solid state and in solution. They are very soluble in chloroform, dichloromethane and acetone, but insoluble in petroleum ether and $n$-hexane. These complexes were characterized by elemental analysis, IR and ${ }^{1} \mathrm{H}-\mathrm{NMR}$. They exhibit similar peaks for the $\mathrm{Cp}$ ring, with a proton ratio of $1: 1: 1: 5$, clearly showing that they are both ortho-cyclopalladated complexes. In general terms, the spectra of $\mathbf{2} \mathbf{a}, \mathbf{b}$ were similar to those of the corresponding $\mathbf{3 a}, \mathbf{b}$. In order to further 
investigate the structures of these complexes and the effect of halogen anions on the structure, their crystal structures have been determined by X-ray diffraction.

\subsection{Crystal Structures of the Complexes 2-3}

Single crystals of these complexes were obtained by crystallization from $\mathrm{CH}_{2} \mathrm{Cl}_{2}$-petroleum ether at room temperature. The molecular structures are shown in Figures 1-3. The crystal structure of $\mathbf{3 b}$ reveals two molecules in the asymmetric unit with different geometry (corresponding values for the second structure are given in brackets). Selected bond lengths and angles are listed in Table 1. The single-crystal X-ray analysis reveal that all complexes display trans configurations in the solid state. The Pd atom in each cyclopalladated unit is in a slightly distorted square-planar environment, being coordinated to phosphorus, chlorine (iodine), nitrogen and the carbon atom of the ferrocenyl moiety. The Pd-N [2.144(7)-2.160(6) $\AA$ ] and Pd-P [2.236(2)-2.246(2) $\AA]$ bond lengths of 3a,b are similar to those of the corresponding 2a,b [2.140(3)-2.1418(19) and 2.2322(11)-2.2369(7) $\AA$ ], while Pd-I [2.6491(10)-2.6752(12) A] bond lengths of $\mathbf{3 a , b}$ are obviously longer than the $\mathrm{Pd}-\mathrm{Cl}[2.3393(8)-2.3642(2) \AA]$ bond lengths in the corresponding adducts $\mathbf{2 a , b}$ [11].

Figure 1. Molecular structure of complex 2a. H atoms are omitted for clarity.

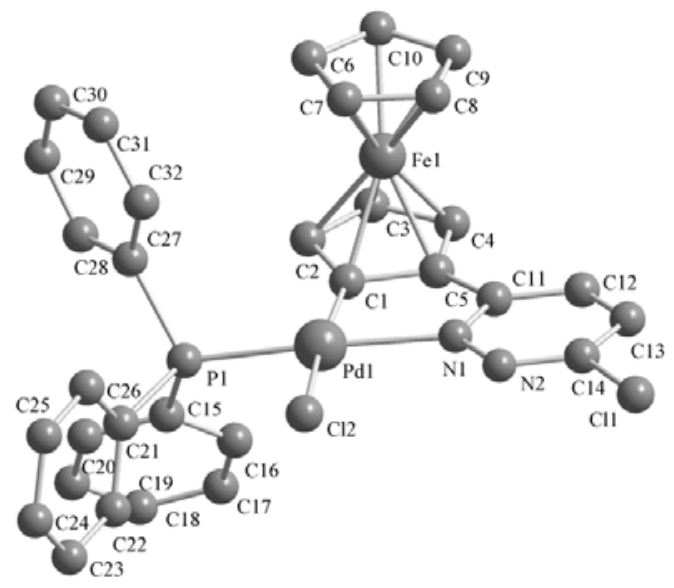

Figure 2. Molecular structure of complex 3a. H atoms are omitted for clarity.

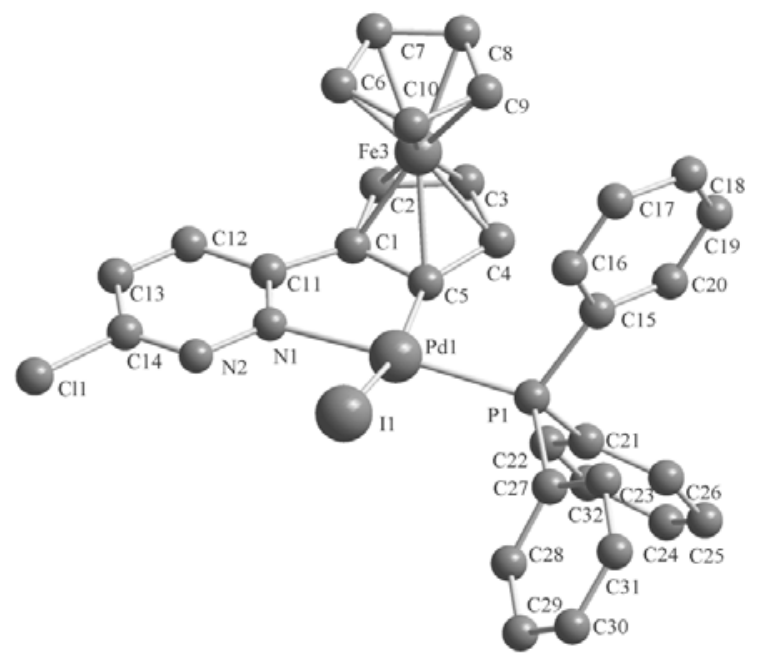


Figure 3. Molecular structure of complex $\mathbf{3 b}$. H atoms are omitted for clarity.

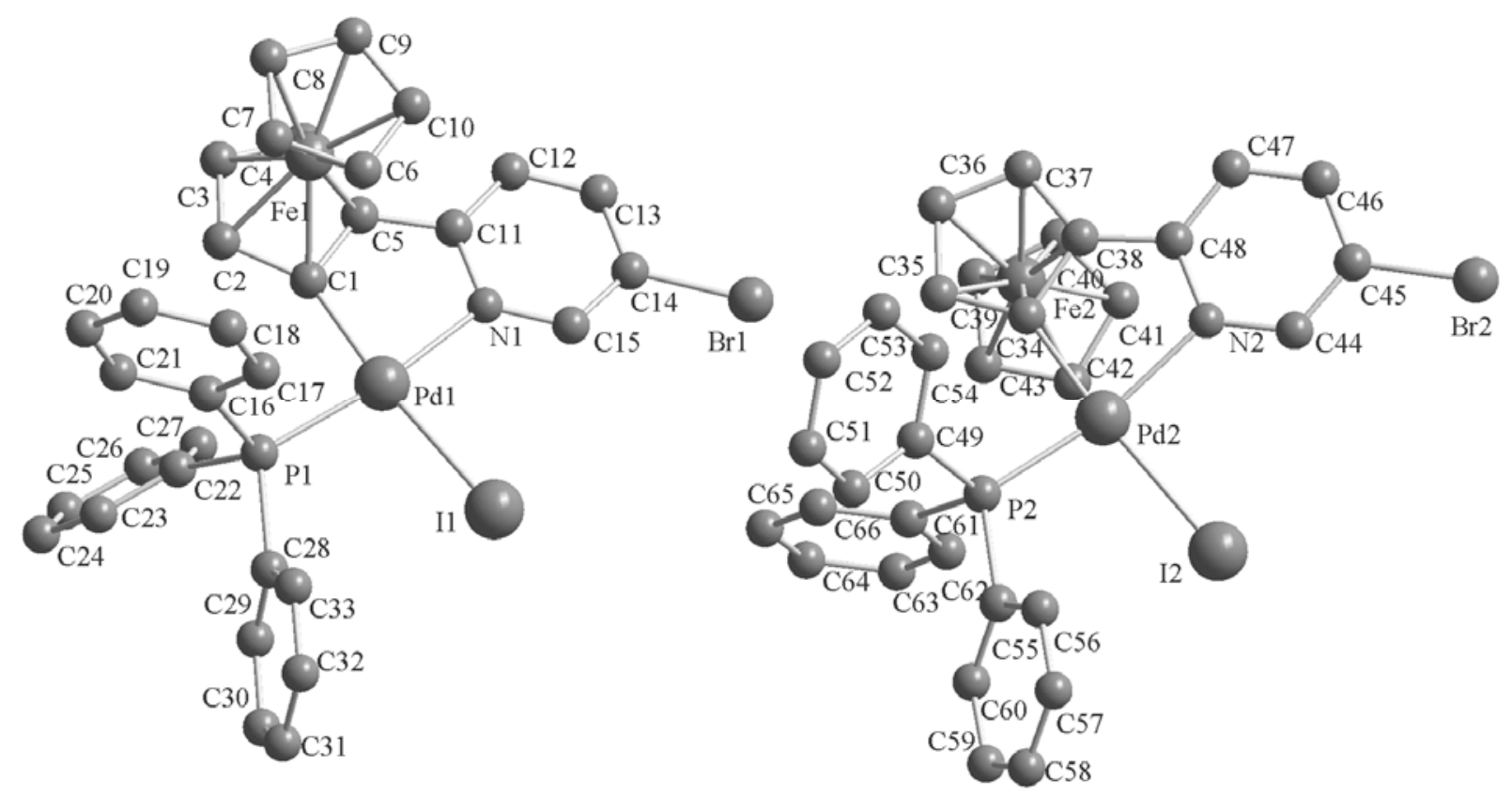

Table 1. Selected bond lengths $(\AA)$ and angles $\left(^{\circ}\right)$ for complexes $\mathbf{2 a}-\mathbf{3 b}$.

\begin{tabular}{llll}
\hline Compound & 2a & 3a & 3b \\
\hline $\operatorname{Pd}(1)-C[(1)$ or $(5)]$ & $1.995(2)$ & $2.003(9)$ & $1.997(7)[2.011(8)]$ \\
$\operatorname{Pd}(1)-\mathrm{N}(1)$ & $2.1418(19)$ & $2.144(7)$ & $2.160(6)[2.160(6)]$ \\
$\operatorname{Pd}(1)-\mathrm{P}(1)$ & $2.2369(7)$ & $2.246(2)$ & $2.238(2)[2.236(2)]$ \\
$\operatorname{Pd}(1)-[\mathrm{Cl}(2)$ or I(1)] & $2.3393(8)$ & $2.6752(12)$ & $2.6491(10)[2.6574(10)]$ \\
$\mathrm{C}[(1)$ or $(5)]-\mathrm{Pd}(1)-\mathrm{N}(1)$ & $80.87(9)$ & $80.3(3)$ & $81.0(3)[81.1(3)]$ \\
$\mathrm{C}[(1)$ or $(5)]-\mathrm{Pd}(1)-\mathrm{P}(1)$ & $92.30(8)$ & $91.8(3)$ & $90.2(2)[91.0(2)]$ \\
$\mathrm{N}(1)-\mathrm{Pd}(1)-[\mathrm{Cl}(2)$ or I(1)] & $92.94(6)$ & $94.79(19)$ & $93.46(17)[93.23(17)]$ \\
$\mathrm{P}(1)-\mathrm{Pd}(1)-[\mathrm{Cl}(2)$ or $\mathrm{I}(1)]$ & $94.17(3)$ & $95.20(6)$ & $95.52(6)[96.40(6)]$ \\
\hline
\end{tabular}

The most striking common feature of the structures of the three palladacycles is the intermolecular $\mathrm{C}-\mathrm{H} \cdots \mathrm{X}(\mathrm{Cl}, \mathrm{Br}, \mathrm{I})$ hydrogen bonds (Figures 4 and 5). The $\mathrm{C}-\mathrm{H} \cdots \mathrm{X}-\mathrm{M}$ hydrogen bonding can be used to assemble transition metal based building blocks into supramolecular structures since the $\mathrm{H}$-bonding acceptor capability of terminal metal-bound chlorine $(\mathrm{M}-\mathrm{X})$ is stronger than their $\mathrm{C}-\mathrm{X}$ analogues in organometallic compounds [12,13]. Basically, the crystal structures of the two complexes $\mathbf{2 a}$ and 3a are quite similar, with chlorine (iodine) anion forming $\mathrm{C}-\mathrm{H} \cdots \mathrm{X}(\mathrm{Cl}, \mathrm{I})$ hydrogen bonds $(\mathrm{Cl} \cdots \mathrm{H}=2.441$ and $\mathrm{I} \cdots \mathrm{H}=3.061 \AA$ ), however, the chlorine atom in the pyridazine ring does not participate in hydrogen bonding. It is noteworthy that intermolecular $\mathrm{C}-\mathrm{H} \cdots \mathrm{Pd}$ hydrogen bonds are present in the crystals of 2a $(\mathrm{Pd} \cdots \mathrm{H}=2.861 \AA)$ and 3a $(\mathrm{Pd} \cdots \mathrm{H}=2.736 \AA)$. Although these interactions have been extensively studied [14], there are a few reports concerning palladacycles [15-17]. Owing to the $\mathrm{C}-\mathrm{H} \cdots \mathrm{X}(\mathrm{Cl}, \mathrm{I})$ and $\mathrm{C}-\mathrm{H} \cdots \mathrm{Pd}$ hydrogen bonds, the crystal structures of the $\mathbf{2} \mathbf{a}$ and $\mathbf{3 a}$ are extended to a 2D network architecture (Figure 4). Unlike 2a and 3a, the complex $\mathbf{3 b}$ has a one-dimensional chain structure formed by $\mathrm{C}-\mathrm{H} \cdots \mathrm{I}$ hydrogen bonds between an iodine atom and the adjacent $\mathrm{C}-\mathrm{H}$ group of the $\mathrm{Cp}$ ring. This is different from that of $\mathbf{2} \mathbf{b}$ which presents $\mathrm{C}-\mathrm{H} \cdots \mathrm{Cl}$ hydrogen bonds between a chlorine atom and the adjacent $\mathrm{C}-\mathrm{H}$ group of the pyridine ring [11]. In addition, $\mathrm{C}-\mathrm{H} \cdots \mathrm{Br}$ hydrogen 
bonds between bromine atom and the adjacent $\mathrm{C}-\mathrm{H}$ group of $\mathrm{Cp}$ ring are also present in the crystal of 3b (Figure 5).

Figure 4. Two-dimensional network structure of complex $\mathbf{2 a}$ formed by $\mathrm{C}-\mathrm{H} \cdots \mathrm{Cl}$ and $\mathrm{C}-\mathrm{H} \cdots \mathrm{Pd}$ hydrogen bonds. Non-hydrogen bonding $\mathrm{H}$ atoms are omitted for clarity.

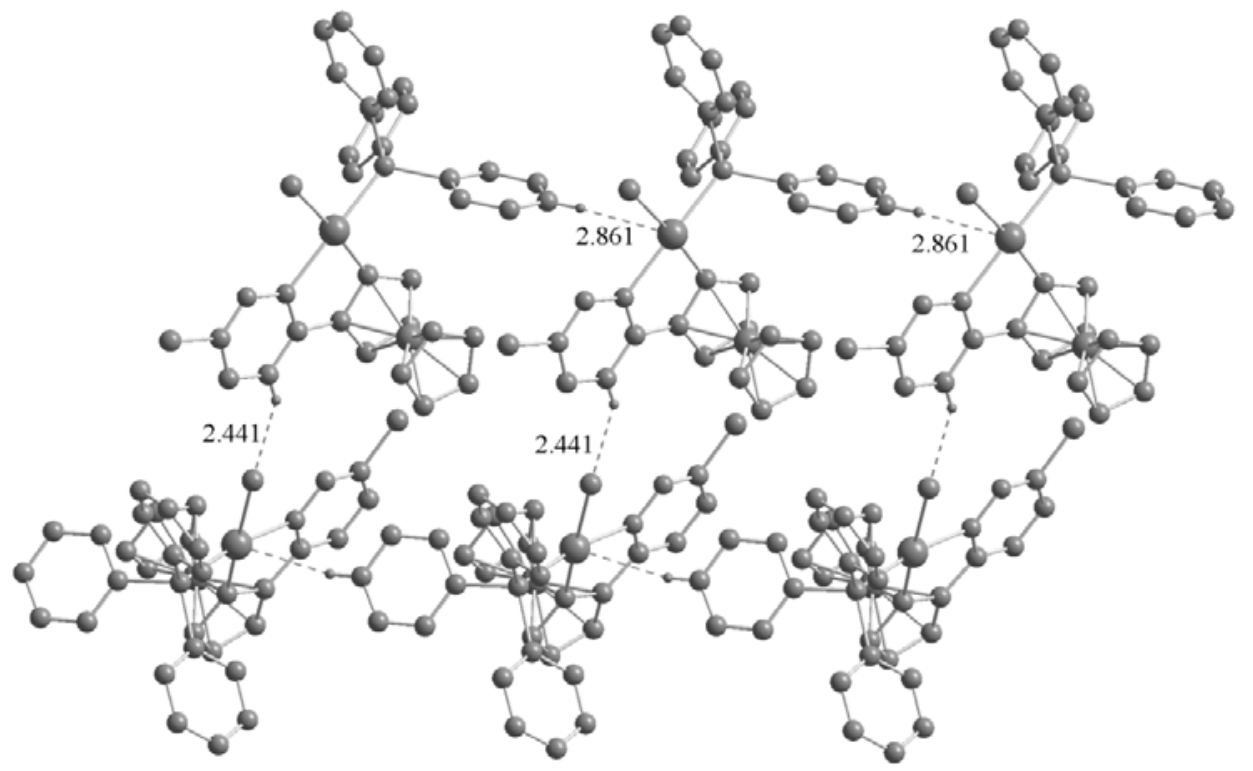

Figure 5. One-dimensional chain structure of complex $\mathbf{3 b}$ formed by $\mathrm{C}-\mathrm{H} \cdots \mathrm{I}(\mathrm{Br})$ hydrogen bonds. Non-hydrogen bonding $\mathrm{H}$ atoms are omitted for clarity.

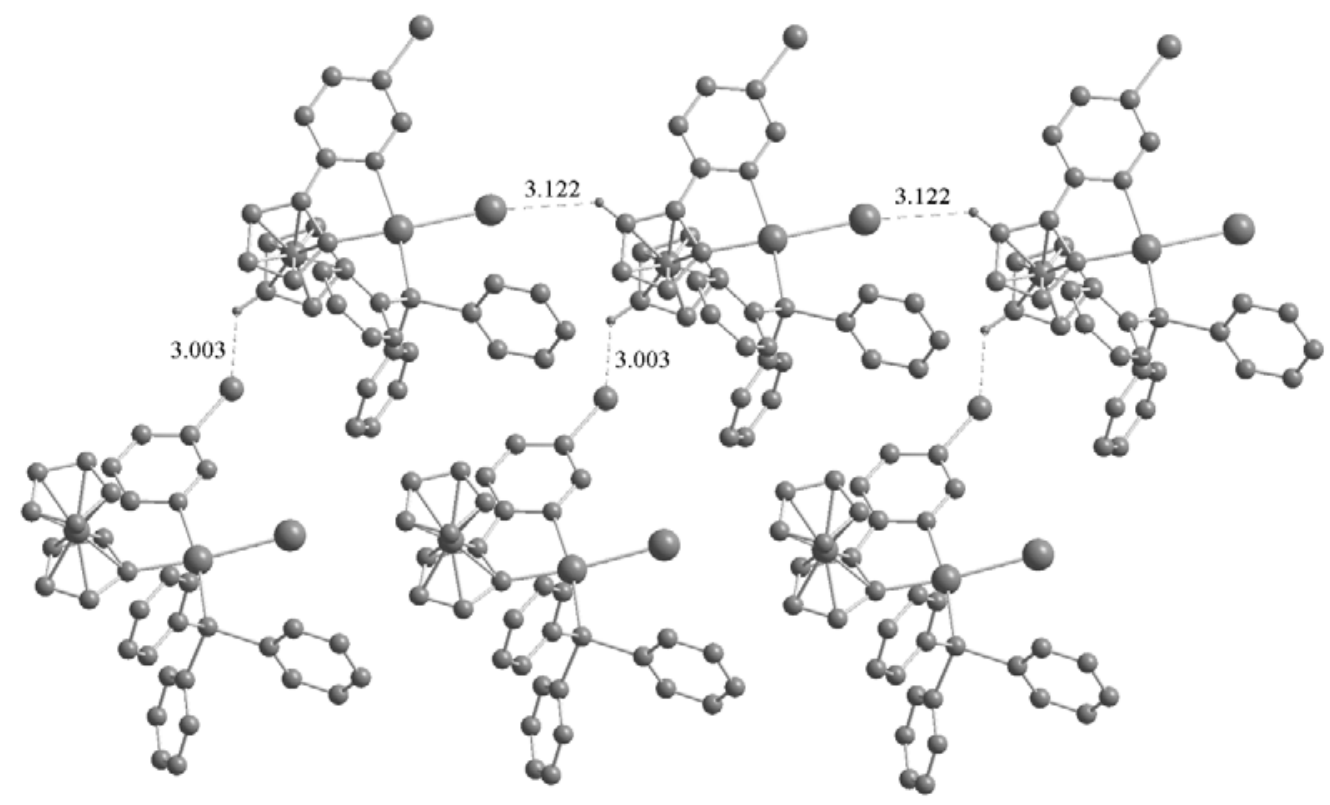

\subsection{Application in Suzuki Reaction}

Phosphine adducts of palladacycles have been successfully used as precatalysts in Suzuki coupling reactions $[4,5]$. The active species was proposed to be a $\mathrm{Pd}(0)$ "Pd-PR ${ }_{3}$ " species and it was shown that the cyclopalladated ligand was released from the metal center during activation of the $\operatorname{Pd}(\mathrm{II})$ precatalyst $[18,19]$. Usually, cyclopalladated ligands have little effect on the catalytic activity, however, 
variation of the anionic ligand $\mathrm{X}(\mathrm{Cl}, \mathrm{Br}, \mathrm{I}, \mathrm{OAc}$, etc. $)$ is found to have some effect on the catalytic activity [20,21]. In order to further investigate the effect of halogen anions on the catalytic activity, we studied the Suzuki reactions catalyzed by the palladacycle adducts $\mathbf{2}-\mathbf{3}$ containing chloride/iodide anions.

In the present study, our initial exploration of the reaction focused on the coupling of 4-bromotoluene with phenylboronic acid. Based on our previous experiments with palladacylic precatalysts for Suzuki coupling reactions [11,17,22], the reaction was performed under nitrogen atmosphere in dioxane in the presence of $\mathrm{Cs}_{2} \mathrm{CO}_{3}$ as base at $100{ }^{\circ} \mathrm{C}$ for $12 \mathrm{~h}$, affording the coupling product in good yields (Table 2, entries 1-4). For an ortho-substituent such as 2-bromotoluene, the yields decreased slightly (entries 5-8). The complexes 2a,b exhibited higher catalytic activity than those of the corresponding $\mathbf{3 a}, \mathbf{b}$ under the same reaction conditions. Even $o$-bromoanisole provide good yields by using $0.5 \mathrm{~mol} \%$ of $\mathbf{2 a , b}$ (entries 9-10). For electron-deficient aryl bromides such as 4-bromonitrobenzene, they could be coupled very efficiently with a catalytic loading as low as $0.1 \mathrm{~mol} \%$ (entries 11-14). We next investigated Suzuki coupling of 4-chlorotoluene under the same reaction conditions. In this case, however, the complexes $\mathbf{2 a}$, $\mathbf{b}$ were almost inactive (entries 15-16). It can be seen from the above results that the activity of adducts in the Suzuki reaction falls in the order $\mathbf{2} \mathbf{a} \sim \mathbf{2} \mathbf{b}>\mathbf{3 a} \sim \mathbf{3 b}$, and the halogen anions have some effect on the catalytic activity, which is consistent with the literature [18,21].

Table 2. Suzuki coupling of aryl halides with phenylboronic acid catalysed by complexes $\mathbf{2}$ and $\mathbf{3}^{\mathrm{a}}$.

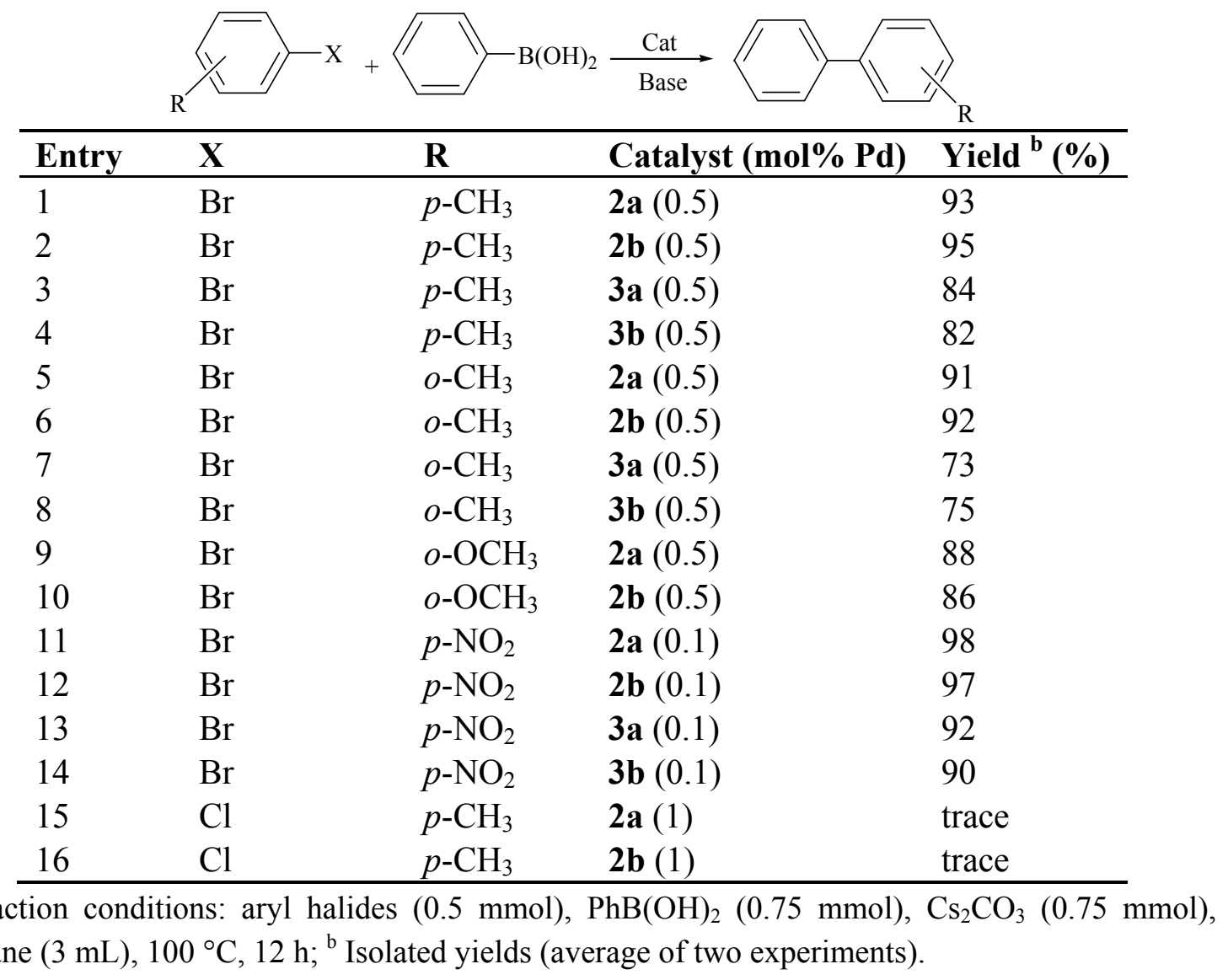




\subsection{Application in Sonogashira Reaction}

The high activity of triphenylphosphine adducts of palladacycles 2-3 in the Suzuki coupling of aryl bromides encouraged us to examine their activity and the effect of halogen anions in the Sonogashira reaction. Usually, the Sonogashira reaction is mediated by a palladium catalyst with copper cocatalyst and amine base. However, many phosphine-palladium complexes are sensitive to both air and moisture, and are both costly and toxic. Moreover, the use of a copper reagent results in contamination of the coupling products with metal residues. Thus a lot of efforts are underway toward developing new palladium catalysts and copper- and amine-free conditions for the Sonogashira reaction [23-26]. Among them, a wide variety of palladacycles have been reported and successfully used in the Sonogashira reaction [5,27-30]. To the best of our knowledge, there was no report concerning the effect of halogen anions on the catalytic activity of palladacycle for the Sonogashira reaction.

The adducts of palladacycles 2-3 were evaluated in arylation reaction of phenylacetylene with aryl halides under copper- and amine-free conditions (Table 3 ). The model reaction of bromobenzene with phenylacetylene produced maximum yields when $\mathrm{CsOAc}$ was used as a base, dimethylacetamide (DMA) as a solvent, and the reaction occurred at $120^{\circ} \mathrm{C}$ for $24 \mathrm{~h}$.

Table 3. Sonogashira reaction of aryl halides with phenylacetylene catalysed by complexes $\mathbf{2}$ and $\mathbf{3}^{\mathrm{a}}$.

\begin{tabular}{|c|c|c|c|c|}
\hline Entry & $\mathbf{X}$ & $\mathbf{R}$ & Catalyst (mol\% Pd) & Yield $^{\mathrm{b}}(\%)$ \\
\hline 1 & $\mathrm{Br}$ & $\mathrm{H}$ & $\mathbf{2 a}(1)$ & 88 \\
\hline 2 & $\mathrm{Br}$ & $\mathrm{H}$ & $\mathbf{2 b}(1)$ & 90 \\
\hline 3 & $\mathrm{Br}$ & $\mathrm{H}$ & $3 \mathbf{a}(1)$ & 96 \\
\hline 4 & $\mathrm{Br}$ & $\mathrm{H}$ & $\mathbf{3 b}(1)$ & 97 \\
\hline 5 & $\mathrm{Br}$ & $o-\mathrm{CH}_{3}$ & $\mathbf{2 a}(1)$ & 81 \\
\hline 6 & $\mathrm{Br}$ & $o-\mathrm{CH}_{3}$ & $2 \mathbf{b}(1)$ & 80 \\
\hline 7 & $\mathrm{Br}$ & $o-\mathrm{CH}_{3}$ & $3 \mathbf{a}(1)$ & 92 \\
\hline 8 & $\mathrm{Br}$ & $o-\mathrm{CH}_{3}$ & $\mathbf{3 b}(1)$ & 94 \\
\hline 9 & $\mathrm{Br}$ & $o-\mathrm{CH}_{3}$ & $3 \mathbf{a}(1)$ & 89 \\
\hline 10 & $\mathrm{Br}$ & $o-\mathrm{CH}_{3}$ & $3 \mathbf{a}(1)$ & 87 \\
\hline 11 & $\mathrm{Br}$ & $p-\mathrm{COCH}_{3}$ & $2 \mathbf{a}(0.1)$ & 91 \\
\hline 12 & $\mathrm{Br}$ & $p-\mathrm{COCH}_{3}$ & $\mathbf{2 b}(0.1)$ & 92 \\
\hline 13 & $\mathrm{Br}$ & $p-\mathrm{COCH}_{3}$ & $\mathbf{3 a}(0.1)$ & 96 \\
\hline 14 & $\mathrm{Br}$ & $p-\mathrm{COCH}_{3}$ & $\mathbf{3 b}(0.1)$ & 98 \\
\hline 15 & $\mathrm{Cl}$ & $p-\mathrm{COCH}_{3}$ & $\mathbf{3 a}(2)$ & 35 \\
\hline 16 & $\mathrm{Cl}$ & $p-\mathrm{COCH}_{3}$ & $\mathbf{3 b}(2)$ & 37 \\
\hline 17 & $\mathrm{Cl}$ & $p-\mathrm{NO}_{2}$ & $3 \mathbf{a}(2)$ & 46 \\
\hline 18 & $\mathrm{Cl}$ & $p-\mathrm{NO}_{2}$ & $\mathbf{3 b}(2)$ & 49 \\
\hline
\end{tabular}

${ }^{\mathrm{a}}$ Reaction conditions: aryl halides $(0.5 \mathrm{mmol})$, arylacetylene $(0.6 \mathrm{mmol})$, CsOAc $(0.75 \mathrm{mmol})$, DMA ( $3 \mathrm{~mL}), 120^{\circ} \mathrm{C}, 24 \mathrm{~h} ;{ }^{\mathrm{b}}$ Isolated yields (average of two experiments). 
All the tested palladacycle precatalysts $2-\mathbf{3}$ showed good activity for the above reaction, giving the coupled product in $88-97 \%$ yields (entries 1-4). It was interesting that the complexes $\mathbf{3 a}, \mathbf{b}$ exhibited higher catalytic activity than those of the complexes $\mathbf{2 a , b}$ in the Sonogashira reaction. This is different from Suzuki reaction. Then, we investigated the Sonogashira coupling of 2-bromotoluene under the same conditions to further compare the effect of halogen anions on the catalytic activity (entries 5-8). Similar to the results of bromobenzene, the activity of adducts falls in the order $\mathbf{3 a} \sim \mathbf{3 b}>\mathbf{2 a} \sim \mathbf{2} \mathbf{b}$. For electron-rich $o$-bromoanisole, the yields decreased slightly, but still were very high $(89 \%$ and $87 \%$, entries 9-10). In the case of activated 4-bromoacetophenone, it was not surprising that good yields were obtained with a catalytic loading as low as $0.1 \mathrm{~mol} \%$ (entries 11-14). Furthermore, Sonogashira reaction of phenylacetylene with aryl chlorides were also studied in this system. For activated chlorides such as 4-chloroacetophenone and 4-chloronitrobenzene, the coupled products could be only produced in 35-49\% yields by using 2 mol\% of $\mathbf{3 a}, \mathbf{b}$ (entries $15-18$ ).

\section{Experimental}

\subsection{General Procedures}

Solvents were dried and freshly distilled prior to use. All other chemicals were commercially available expect for the chloride-bridged palladacyclic dimers $\mathbf{1} \mathbf{a}, \mathbf{b}$ and $\mathbf{2} \mathbf{b}$ were prepared according to published procedures [10,11]. All other chemicals were used as purchased. Elemental analyses were determined with a Thermo Flash EA 1112 elemental analyzer. IR spectra were collected on a Bruker VECTOR22 spectrophotometer using $\mathrm{KBr}$ pellets. ${ }^{1} \mathrm{H}-\mathrm{NMR}$ spectra were recorded on a Bruker DPX-400 spectrometer in $\mathrm{CDCl}_{3}$ with TMS as an internal standard.

\subsection{The Synthesis of Complex 2a}

A solution of chloride-bridged palladacyclic dimer $1 \mathrm{a}(0.1 \mathrm{mmol})$ and triphenylphosphine ( $0.22 \mathrm{mmol})$ in $\mathrm{CH}_{2} \mathrm{Cl}_{2}(10 \mathrm{~mL})$ was stirred at room temperature for $30 \mathrm{~min}$. The product was separated by passing through a silica gel column with dichloromethane as eluent. The first band was collected to afford complex $2 \mathbf{a}$ after the evaporation of the solvent. $\left[\mathrm{PdCl}\left\{\left[\left(\eta^{5}-\mathrm{C}_{5} \mathrm{H}_{5}\right)\right] \mathrm{Fe}\left[\left(\eta^{5}-\mathrm{C}_{5} \mathrm{H}_{3}\right)-\mathrm{N}_{2} \mathrm{C}_{4} \mathrm{H}_{2}-\mathrm{Cl}\right]\right\} \mathrm{PPh}_{3}\right]$ (2a): Yield 90\%. Found (\%): C, 55.1; H, 3.4; N, 4.2. Calc. (\%) for $\mathrm{C}_{32} \mathrm{H}_{25} \mathrm{Cl}_{2} \mathrm{FeN}_{2} \mathrm{PPd}$ : C, 54.8; H, 3.6; $\mathrm{N}, 4.0$. IR (KBr, cm $\left.{ }^{-1}\right): 3045,1584,1533,1472,1435,1392,1376,1273,1161,1097,999,855,815$, 743, 689. ${ }^{1} \mathrm{H}-\mathrm{NMR}\left(\mathrm{CDCl}_{3}\right): \delta 7.84-7.80(\mathrm{~m}, 6 \mathrm{H}, \mathrm{ArH}), 7.40-7.33(\mathrm{~m}, 11 \mathrm{H}, \mathrm{ArH}), 4.65\left(\mathrm{~s}, 1 \mathrm{H}, \mathrm{C}_{5} \mathrm{H}_{3}\right)$, $4.22\left(\mathrm{~s}, 1 \mathrm{H}, \mathrm{C}_{5} \mathrm{H}_{3}\right), 3.75\left(\mathrm{~s}, 5 \mathrm{H}, \mathrm{C}_{5} \mathrm{H}_{5}\right), 3.43\left(\mathrm{~s}, 1 \mathrm{H}, \mathrm{C}_{5} \mathrm{H}_{3}\right)$.

\subsection{General Method for the Synthesis of Complexes 3a,b}

A solution of the chloride anion-containing triphenylphosphine palladacycle adduct $2(0.1 \mathrm{mmol})$ and $\mathrm{NaI}(0.2 \mathrm{mmol})$ in acetone $(10 \mathrm{~mL})$ was stirred at room temperature for $3 \mathrm{~h}$. The product was separated by passing through a silica gel column with dichloromethane as eluent. The first band was collected to afford the corresponding complex $\mathbf{3}$ after evaporation of the solvent.

$\left[\mathrm{PdI}\left\{\left[\left(\eta^{5}-\mathrm{C}_{5} \mathrm{H}_{5}\right)\right] \mathrm{Fe}\left[\left(\eta^{5}-\mathrm{C}_{5} \mathrm{H}_{3}\right)-\mathrm{N}_{2} \mathrm{C}_{4} \mathrm{H}_{2}-\mathrm{Cl}\right]\right\} \mathrm{PPh}_{3}\right](\mathbf{3 a})$ : Yield 96\%. Found (\%): C, 48.7; H, 3.1; N, 3.8. Calc. (\%) for $\mathrm{C}_{32} \mathrm{H}_{25} \mathrm{ClFeIN}_{2} \mathrm{PPd}$ : C, 48.5; H, 3.2; N, 3.5. IR (KBr, $\left.\mathrm{cm}^{-1}\right)$ : 3043, 1582, 1533, 1470 , 
1433, 1392, 1374, 1268, 1158, 1091, 998, 838, 824, 749, 680. ${ }^{1} \mathrm{H}-\mathrm{NMR}\left(\mathrm{CDCl}_{3}\right): \delta 7.85-7.81(\mathrm{~m}, 6 \mathrm{H}$, ArH), 7.44-7.38 (m, 11H, ArH), $4.57\left(\mathrm{~s}, 1 \mathrm{H}, \mathrm{C}_{5} \mathrm{H}_{3}\right), 4.19\left(\mathrm{~s}, 1 \mathrm{H}, \mathrm{C}_{5} \mathrm{H}_{3}\right), 3.70\left(\mathrm{~s}, 5 \mathrm{H}, \mathrm{C}_{5} \mathrm{H}_{5}\right), 3.59$ $\left(\mathrm{s}, 1 \mathrm{H}, \mathrm{C}_{5} \mathrm{H}_{3}\right)$.

$\left[\operatorname{PdI}\left\{\left[\left(\eta^{5}-\mathrm{C}_{5} \mathrm{H}_{5}\right)\right] \mathrm{Fe}\left[\left(\eta^{5}-\mathrm{C}_{5} \mathrm{H}_{3}\right)-\mathrm{NC}_{5} \mathrm{H}_{3}-\mathrm{Br}\right]\right\} \mathrm{PPh}_{3}\right](\mathbf{3 b})$ : Yield 97\%. Found (\%): C, 56.9; H, 3.9; N, 4.4. Calc. (\%) for $\mathrm{C}_{35} \mathrm{H}_{31} \mathrm{Cl}_{2} \mathrm{FeN}_{2} \mathrm{PPd}$ : C, 56.5; H, 4.2; N, 4.7\%. IR (KBr, $\left.\mathrm{cm}^{-1}\right)$ : 3066, 2922, 1594, 1494, 1479, 1432, 1386, 1152, 1107, 1090, 1024, 998, 820, 746, 668. ${ }^{1} \mathrm{H}-\mathrm{NMR}\left(\mathrm{CDCl}_{3}\right): \delta 9.87$ (s, 1H, PyH), 7.83-7.78 (m, 6H, ArH), 7.75 (d, 1H, PyH), 7.45-7.39 (m, 9H, ArH), 7.17 (d, 1H, PyH), 4.57 (s, 1H, $\left.\mathrm{C}_{5} \mathrm{H}_{3}\right), 4.05\left(\mathrm{~s}, 1 \mathrm{H}, \mathrm{C}_{5} \mathrm{H}_{3}\right), 3.65\left(\mathrm{~s}, 5 \mathrm{H}, \mathrm{C}_{5} \mathrm{H}_{5}\right), 3.46\left(\mathrm{~s}, 1 \mathrm{H}, \mathrm{C}_{5} \mathrm{H}_{3}\right)$.

\subsection{General Procedure for the Arylation Reactions}

A prescribed amount of catalyst, aryl halide $(0.5 \mathrm{mmol})$, phenyl boronic acid $(0.75 \mathrm{mmol})$ or alkyne $(0.6 \mathrm{mmol})$ and the selected base $(1.5 \mathrm{mmol})$ in solvent $(3 \mathrm{~mL})$ were placed in a Schlenk tube under nitrogen. The reaction mixture was heated at $100{ }^{\circ} \mathrm{C}-120{ }^{\circ} \mathrm{C}$ for $12-24 \mathrm{~h}$, then cooled and quenched with water. The reaction mixture was extracted three times with $\mathrm{CH}_{2} \mathrm{Cl}_{2}$, then the combined organic layers were washed with water, dried $\left(\mathrm{MgSO}_{4}\right)$, and evaporated to dryness. The products were isolated by flash chromatography on silica gel using petroleum ether as eluent and analyzed by ${ }^{1} \mathrm{H}-\mathrm{NMR}$.

\subsection{Crystal Structure Determination}

Crystallographic data for complexes 2a and 3a,b were collected on a Bruker SMART APEX-II CCD diffractometer euuipped with a graphite monochromator at $296 \mathrm{~K}$ using Mo-Ka radiation $(\lambda=0.071073 \AA)$. The data were corrected for Lorentz polarization factors as well as for absorption. Structures were solved by direct methods and refined by full-matrix least-squares methods on $F^{2}$ with the SHELX-97 program [31]. All non-hydrogen atoms were refined anisotropically, while hydrogen atoms were placed in geometrically calculated positions. Crystal data and structure refinements are summarized in Table 4. CCDC reference numbers 875474-875476 conta1n the crystallographyic data for 2a and 3a,b, respectively. These data can be obtained free of charge from The Cambridge Crystallographic Data Centre via www.ccdc.cam.ac.uk/ data_request/cif.

Table 4. Crystallographic data and structure refinement for $\mathbf{2 a}-\mathbf{3 b}$.

\begin{tabular}{llll}
\hline Compound & $\mathbf{2 a}$ & $\mathbf{3 a}$ & $\mathbf{3 b}$ \\
\hline Elemental formula & $\mathrm{C}_{32} \mathrm{H}_{25} \mathrm{Cl}_{2} \mathrm{FeN}_{2} \mathrm{PPd}$ & $\mathrm{C}_{32} \mathrm{H}_{25} \mathrm{ClFeIN}_{2} \mathrm{PPd}$ & $\mathrm{C}_{33} \mathrm{H}_{26} \mathrm{BrFeINPPd}$ \\
Formula mass & 701.66 & 793.11 & 836.58 \\
Crystal system & Monoclinic & Monoclinic & Triclinic \\
Space group & $\mathrm{P} 2(1) / \mathrm{c}$ & $\mathrm{P} 2(1) / \mathrm{c}$ & $\mathrm{P}-1$ \\
Crystal size $/ \mathrm{mm}$ & $0.38 \times 0.27 \times 0.16$ & $0.35 \times 0.27 \times 0.18$ & $0.34 \times 0.26 \times 0.17$ \\
$\mathrm{a} / \AA$ & $9.2765(7)$ & $8.835(3)$ & $10.410(3)$ \\
$\mathrm{b} / \AA$ & $15.8968(13)$ & $16.756(6)$ & $16.185(4)$ \\
$\mathrm{c} / \AA$ & $19.7419(16)$ & $20.546(7)$ & $17.981(4)$ \\
$\alpha /{ }^{\circ}$ & 90 & 90 & $85.597(3)$ \\
$\beta /{ }^{\circ}$ & $90.8120(10)$ & $90.789(4)$ & $86.449(3)$ \\
$\gamma /{ }^{\circ}$ & 90 & 90 & $81.452(3)$ \\
\hline
\end{tabular}


Table 4. Cont.

\begin{tabular}{llll}
\hline Compound & 2a & 3a & 3b \\
\hline $\mathrm{V} / \AA^{3}$ & $2911.0(4)$ & $3041.4(18)$ & $2983.0(12)$ \\
$\mathrm{D}_{\mathrm{c}} / \mathrm{g} \mathrm{cm}^{-3}$ & 1.601 & 1.732 & 1.863 \\
$\mathrm{Z}$ & 4 & 4 & 4 \\
Data/restraints/ & $5419 / 0 / 352$ & $5623 / 0 / 352$ & $10997 / 0 / 703$ \\
parameters & & & \\
$\mathrm{R}_{1}, \mathrm{wR}_{2}[\mathrm{I}>2 \sigma(\mathrm{I})]^{\mathrm{a}}$ & $0.0251,0.0551$ & $0.0595,0.1755$ & $0.0525,0.1108$ \\
${ }^{\mathrm{a}} \mathrm{R}_{1}=\Sigma|| \mathrm{F}_{\mathrm{o}}|-| \mathrm{F}_{\mathrm{c}} \| / \Sigma\left|\mathrm{F}_{\mathrm{o}}\right|, \mathrm{wR}_{2}=\left[\Sigma\left(\mathrm{F}_{\mathrm{o}}{ }^{2}-\mathrm{F}_{\mathrm{c}}{ }^{2}\right)^{2} / \Sigma \mathrm{w}\left(\mathrm{F}_{\mathrm{o}}{ }^{2}\right)^{2}\right]^{1 / 2}$ & \\
\hline
\end{tabular}

\section{Conclusions}

In summary, we have prepared and characterized three new triphenylphosphine adducts of palladacycles containing chloride/iodide anions. Single-crystal X-ray analysis confirms that there are intermolecular $\mathrm{C}-\mathrm{H} \cdots \mathrm{X}(\mathrm{Cl}, \mathrm{Br}, \mathrm{I})$ hydrogen bonds in the crystals of $\mathbf{2} \mathbf{a}-\mathbf{3 b}$. Their performance and the effect of halogen anions were evaluated in arylation reactions. Currently, further investigation into the mechanism of these reactions, and other applications involving this class of complexes in other coupling reactions are in progress.

\section{Acknowledgments}

We are grateful to the National Natural Science Foundation of China (No. 20902043) and the Natural Science Foundation of Henan Province (No. 102300410220) and Luoyang Tackle Key Problem of Science and Technology (No. 1001060A) for financial support of this work.

\section{References}

1. Tsuji, J. Palladium Reagents and Catalysts; Wiley: Chichester, UK, 2004.

2. Phan, N.T.S.; Sluys, M.V.D.; Jones, C.W. On the nature of the active species in palladium catalyzed Mizoroki-Heck and suzuki-miyaura couplings-homogeneous or heterogeneous catalysis, a critical review. Adv. Synth. Catal. 2006, 348, 609-679.

3. Chinchilla, R.; Nájera, C. The Sonogashira reactions: A booming methodology in synthetic organic chemistry. Chem. Rev. 2007, 107, 874-922.

4. Bedford, R.B. Palladacyclic catalysts in C-C and C-Heteroatom bond-forming reactions. Chem. Commun. 2003, 1787-1796.

5. Dupont, J.; Pfeffer, M. Palladacycles; Wiley-VCH: Weinheim, Germany, 2008.

6. Alonso, D.A.; Nájera, C. Oxime-derived palladacycles as source of palladium nanoparticles. Chem. Soc. Rev. 2010, 39, 2891-2902.

7. Xu, C.; Wang, Z.Q.; Fu, W.J.; Lou, X.H.; Li, Y.F.; Cen, F.F.; Ma, H.J.; Ji, B.M. Synthesis and Structural Characterization of Monophosphine-Cyclopalladated Ferrocenylpyrimidine Complexes and Reusable Catalytic System for Amination of Hindered Aryl Chlorides in PEG-400. Organometallics 2009, 28, 1909-1916. 
8. Xu, C.; Zhang, Y.P.; Wang, Z.Q.; Fu, W.J.; Hao, X.Q.; Xu, Y.; Ji, B.M. Design and synthesis of tetranuclear cluster monophosphine-cyclopalladated ferrocenylpyrimidinone complexes from the palladium-catalyzed hydroxylation of chloropyrimidine. Chem. Commun. 2010, 46, 6852-6854.

9. Xu, C.; Li, H.M.; Liu, H.; Zhang, Z.Q.; Wang, Z.Q.; Fu, W.J.; Zhang, Y.Q. N-Heterocyclic carbene adducts of cyclopalladated ferrocenylpyridine: synthesis, structural characterization and reusable catalytic system for Suzuki and amination of aryl chlorides in poly(ethylene glycol-400) Inorg. Chim. Acta. 2012, 386, 22-26.

10. Xu, C.; Li, H.M.; Wang, Z.Q.; Fu, W.J.; Zhang, Y.Q.; Ji, B.M. N-heterocyclic carbene adducts of cyclopalladated ferrocenylpyridazine: Synthesis, structural characterization and application in $\alpha$-arylation of ketones with aryl chlorides. Aust. J. Chem. 2012, 65, 366-370.

11. Xu, C.; Wang, Z.Q.; Zhang, Y.P.; Dong, X.M.; Hao, X.Q.; Fu, W.J.; Ji, B.M.; Song, M.P. Synthesis and Structural Characterization of Palladacycles with Polydentate Ligands via the Stepwise Coupling Route: Palladacycles Containing Halide as Efficient Catalysts and Substrates. Eur. J. Inorg. Chem. 2011, 4878-4888.

12. Aakeröy, C.B.; Evans, T.A.; Seddon, K.R.; Pálinkó, I. The $\mathrm{C}-\mathrm{H} \cdots \mathrm{Cl}$ hydrogen bond: Does it exit? New J. Chem. 1999, 23, 145-152.

13. Brammer, L.; Bruton, E.A.; Sherwood, P. Understanding the Behavior of Halogens as Hydrogen Bond Acceptors. Cryst Growth Des 2001, 1, 277-290.

14. Braga, D.; Grepioni, F.; Tedesco, E.; Biradha, K.; Desiraju, G.R. Hydrogen Bonding in Organometallic Crystals. 6. $\dagger \mathrm{X}-\mathrm{H}---\mathrm{M}$ Hydrogen Bonds and $\mathrm{M}---(\mathrm{H}-\mathrm{X})$ Pseudo-Agostic Bonds Organometallics 1997, 16, 1846-1856.

15. Neve, F.; Crispini, A. N,N'-Dodecamethylene-bis(pyridinium) goes lamellar. Role of C-H $\cdots \mathrm{I}$, $\mathrm{C}-\mathrm{H} \cdots \mathrm{M}$ and $\mathrm{I} \cdots \mathrm{I}$ interactions in the crystal structure of its hexaiododipalladate derivative. CrystEngComm 2003, 5, 265-268.

16. Troitskaya, L.L.; Starikova, Z.A.; Demeshchik, T.V.; Ovseenko, S.T.; Vorontsov, E.V.; Sokolov, V.I. Abnormal cyclopalladation of Schiff based made of metallocenyl aldehydes and $\alpha$-ferrocenylethylamine: Unexpected formation of the heteroannular 3-atomic bridge. J. Organomet. Chem. 2005, 690, 3976-3982.

17. Xu, C.; Gong, J.F.; Yue, S.F.; Zhu, Y.; Wu, Y.J. Tricyclohexylphosphine-cyclopalladated ferr ocenylimine complexes: synthesis, crystal structures and application in Suzuki and Heck reactions. Dalton. Trans. 2006, 4730-4739.

18. Bedford, R.B.; Cazin, C.S.J.; Holder, D. The development of palladium catalysts for C-C and C-heteroatom bond forming reactions of aryl chloride substrates. Coord. Chem. Rev. 2004, 248, 2283-2321.

19. Farina, V. High-Turnover Palladium Catalysts in Cross-Coupling and Heck Chemistry: A Critical Overview. Adv. Synth. Catal. 2004, 346, 1553-1582.

20. Herrmann, W.A.; Böhm, V.P.W.; Reisinger, C.P. Application of palladacycles in Heck type reactions. J. Organomet. Chem. 1999, 576, 23-41.

21. Bedford, R.B.; Cazin, C.S.J. High-Activity Catalysts for Suzuki Coupling and Amination reactions with Deactivated Aryl Chloride Substrates: Importance of the Palladium Source. Organometallics 2003, 22, 987-999. 
22. Xu, C.; Gong, J.F.; Guo, T.; Zhang, Y.H.; Wu, Y.J. Cyclopalladated ferrocenylimine complexes with dicyclohexylphosphinobiphenyl ligand ligands: Synthesis, crystal structures and their use highly efficient catalysts for Suzuki reaction of aryl chlorides. J. Mol. Catal. A 2008, 279, 69-76.

23. Chinchilla, R.; Nájera, C. Recent advances in Sonogashira reactions. Chem. Soc. Rev. 2011, 40, 5084-5121.

24. Doucet, H.; Hierso, J.C. Palladium-Based Catalytic Systems for the Synthesis of Conjugated Enynes by Sonogashira Reactions and Related Alkynylations. Angew. Chem. Int. Ed. 2007, 46, 834-871.

25. Inés, B.; SanMartin, R.; Churruca, F.; Domínguez, E.; Urtiaga, M.K.; Arriortua, M.I. A nonsymmetric pincer-type palladium catalyst in Suzuki, Sonogashira and Hiyama coupling in neat water. Organometallics 2008, 27, 2833-2839.

26. Samantaray, M.K.; Shaikh, M.M.; Ghosh, P. Copper-free and amine-free Sonogashira coupling in air in a mixed aqueous medium by palladium complexes of N/O-functionalized N-heterocyclic carbenes. J. Organomet. Chem. 2009, 694, 3477-3486.

27. Alonso, D.A.; Botella, L.; Nájera, C.; Pacheco, M.C. Synthetic applications of oxime-derived palladacycles as versatile catalysts in cross-coupling reactions. Synthesis 2004, 1713-1718.

28. Consorti, C.S.; Fabricio, R.F.; Rominger, F.; Dupont, J. A simple and efficient copper-free catalytic system based on a palladacycle for the arylation of alkynes. Adv. Synth. Catal. 2006, 348, $133-141$.

29. Yang, F.; Cui, X.L.; Li, Y.N.; Zhang, J.L.; Ren, G.R.; Wu, Y.J. Cyclopalladated ferrocenylimines: efficient catalysts for homocoupling and Sonogashira reaction of terminal alkynes. Tetrahedron 2007, 63, 1963-1969.

30. Zhang, B.S.; Wang, C.; Gong, J.F.; Song, M.P. Facile synthesis of achiral and chiral PCN pincer palladium(II) complexes and their application in the Suzuki and copper-free Sonogashira cross-coupling reactions. J. Organomet. Chem. 2009, 694, 2555-2561.

31. Sheldrick, G.M. A short history of SHELX. Acta Crystallogr. Sect. A 2008, 64, 112-122.

Sample Availability: Samples of the complexes 1-3 are available from the authors.

(C) 2012 by the authors; licensee MDPI, Basel, Switzerland. This article is an open access article distributed under the terms and conditions of the Creative Commons Attribution license (http://creativecommons.org/licenses/by/3.0/). 